\title{
STRANGE BEDFELLOWS IN THE PERSONAL COMPUTER INDUSTRY: TECHNOLOGY ALLIANCES BETWEEN IBM AND APPLE
}

\author{
John Hagedoorn* \\ Elias Carayannis** \\ Jeffrey Alexander ***
}

February 2000

* MERIT, Faculty of Economics and Business Administration, University of Maastricht, PO Box 616, 6200 MD Maastricht, The Netherlands, Phone: (31)43-3883897, Fax: (31)433884893, Email: j.hagedoorn@ mw.unimaas.nl

**Faculty of Management of Science, Technology and Innovation Program, Management Science Department, School of Business and Public Management, The George Washington University, Washington, DC 20052, USA, Phone: (202) 994 4062, Fax: (202) 994 4930, Email: caraye@gwu.edu

***Doctoral Candidate, Management of Science, Technology and Innovation Program, Management Science Department, School of Business and Public Management, The George Washington University, Washington, DC 20052, USA, Email: jeffalex@ wcore.com 


\title{
STRANGE BEDFELLOWS IN THE PERSONAL COMPUTER INDUSTRY: TECHNOLOGY ALLIANCES BETWEEN IBM AND APPLE
}

\author{
Abstract \\ Until recently technological development in the personal computer industry could be \\ characterized by the competition between two basic designs. The current dominant design in \\ this industry is associated with the IBM and Microsoft personal computing architecture. The \\ other version of personal computing originated in the Macintosh computer from Apple \\ Computer Company. In recent years we also see an increasing number of alliances between \\ IBM and Apple. Joint technological development appears to be a major and somewhat \\ surprising objective of these alliances. This paper analyzes the technology alliances between \\ these companies in the context of recent technological changes, focusing on the timing and \\ the objectives of these alliances. Technology partnering between these proponents of \\ competing basic designs are found to only materialize several years after the DOS-based \\ design of IBM and Microsoft had become dominant. This study is of a qualitative and \\ exploratory nature, using both a small data set and two case studies. \\ (technology, basic designs, alliances)
}




\section{INTRODUCTION}

Technological development in the personal computer industry was, until recently, clearly marked by the competition between two basic designs. One design is associated with the IBM and Microsoft personal computing architecture, originally based on the Disk Operating System (DOS). The other design for personal computing originated in the Macintosh approach as developed by Apple Computer Company. These two approaches materialized into rather different basic designs, of which one design, the IBM-Microsoft version, became dominant.

However, in recent years we also notice an increasing number of alliances between Apple and IBM, the strange bedfellows that we refer to in the title of this paper. Joint technological development appears to be a major and somewhat surprising objective of these alliances. 'Surprising' because an intuitive understanding of technology alliances would suggest that companies that are so closely associated with different, competing approaches to a particular field of technology are not expected to be candidates for any sort of joint effort.

In the following we will present an analysis of technology partnering between IBM and Apple in which we first present a general background for understanding technological development in the personal computer industry applying concepts such as technological paradigms, basic designs and dominant designs. This illustrates the technological development that took place in the personal computer industry, providing a context for understanding the nature of technology partnering between apparent rival companies such as IBM and Apple.

The technology alliances between both companies will be analyzed in particular in terms of their timing and the focus of these alliances. Our study is of a qualitative and exploratory nature, using a small data set and a small number of case studies. We will discuss our main 
research questions as propositions that are further discussed and elaborated upon in the empirical analysis.

\section{TECHNOLOGICAL PARADIGMS AND BASIC DESIGNS IN THE PERSONAL COMPUTER INDUSTRY}

Notions such as technological paradigm, basic design and dominant design are frequently referred to in the literature on technology history, the economics of technological change, technology management, and organization studies to explain patterns in technological development. However, different studies use varying definitions for each of these concepts (Abernathy and Utterback, 1978; Anderson and Tushman, 1990; Clark and Juma, 1987; Dosi 1982; Freeman and Soete 1987; Rosenkopf and Tushman, 1994; Sahal, 1981). In the following we will discuss these concepts and their mutual relationship in the context of the, for this study, relevant technological developments.

\section{The development of a mature technological paradigm in the personal computer industry}

Technological paradigms can be interpreted as the technology-related counterpart of Kuhn's scientific paradigm (Kuhn, 1974). The concept of a paradigm refers to a body of knowledge and practices which serves to define the problems and methods of a field of science or technology. Understanding technological development in terms of a technological paradigm stresses the particular role that a disciplinary matrix or a community of practitioners plays in defining a field of technology. Dosi (1982) defines a technological paradigm as a model and a pattern of solution for selected technological problems, based on selected principles derived from natural sciences and on selected material technologies. Within technological paradigms rules building both negative and positive heuristics are formulated to stimulate research in certain directions. However, in particular during early phases of paradigmatic development 
we can expect competing approaches that are using different technologies to solve similar sets of technical challenges.

The different ways in which IBM and Apple developed their technologies for the personal computer industry are clear examples of different approaches within an emerging technological paradigm. ${ }^{1}$ These alternative approaches were based on technologies developed in the 1970s by Apple Computer Company for the Apple I and II, challenged by the introduction of the IBM PC in the early 1980s. They both centred around the perception of data and word processing using a single microprocessor as the central processing unit for executing instructions entered in a specific syntax, such as the BASIC computer language or the Microsoft DOS command structure. Technological improvements within this paradigm were derived primarily from the development of more complex and involved programs executed with more powerful microprocessors.

The IBM approach to personal computing as found in the PC, introduced in 1981, is a representative result of an early phase of the current technological paradigm in personal computing. The IBM perception of personal computing via the PC and its operating system from Microsoft (MS-DOS) was designed by technologists for use by technologists. Users with some technical ability could open the computer, add and remove components, and otherwise modify the system, but such activities required an understanding of the technical principles and specific language of computer technology. The IBM PC integrated the hobbyist approach of Apple, with a focus on achieving a minimum level of functionality with a sparing use of resources, and the technical experience of IBM, with a focus on serving a community of specialists and efficiently integrating components from various sources.

The 'philosophy' behind the introduction of the Macintosh computer to the mass market in 1984 represented a change within the existing technological paradigm. First, the Macintosh approach introduced the concept of 'user-friendliness' with the graphical user interface 
(GUI) using icons on a desktop to represent programs and files. Second, the overall architecture of the Macintosh was conceived as a single integrated unit, with the monitor, disk drive, and central processing unit CPU contained in a single case. Other peripheral devices, such as printers, could be connected via pre-installed ports, instead of inserting the interface cards directly into the computer's main board. Third, and most important, the Macintosh was developed as an integrated system which made the technical aspects of the computer opaque to the user.

The emergence of a third approach combining these early approaches can be characterized as a process of paradigmatic unification, realized in the Wintel architecture. This architecture combines Microsoft's Windows operating system with the Intel microprocessor. The basic idea behind the Windows software was to integrate the core technologies of the Macintosh, such as the GUI and the mouse, and also removed the user from direct manipulation of the underlying operating system. The focus on user friendliness affected only the surface of the computer, as the underlying software and hardware architecture followed the basic IBM-DOS approach. The Wintel approach further assumed an environment where computing power and resources increased almost without limit, driven by 'Moore's Law'on the evolution of the microprocessor. Thus, Windows and its later descendants were developed primarily to achieve the functionality of the Macintosh on the IBM-DOS platform, but the values of elegance and simplicity were lost as the resulting system grew more complex.

The history of these competing approaches also illustrates how Apple and IBM, as the pioneers of the early paradigm of personal computing, failed to play a major role in the more recent developments. The primary carrier of the mature paradigm was instead Microsoft, which grew to become a major supplier of both operating systems (Windows) and application programs for that system. However, given the maturity of the current paradigm we also note that new demands that deal with multimedia technology, merging communication and data 
processing technologies, and advanced data processing demand new technological solutions that are not readily suggested by the existing paradigm, and thus require the development of a new approach to computing.

\section{Basic and dominant designs in the personal computer industry}

The concept frequently used to analyse competing technologies at a lower level of abstraction than a paradigm, referring to the actual technological artifacts, is that of a basic design. Nelson and Winter (1977) and others introduced this concept, which is somewhat comparable to a meta-production function as found in Schumpeterian economics. ${ }^{2}$ However, the concept of a basic design is more concrete than a meta-production function and can be seen as a concrete model for further development with clear 'puzzle-solutions' as in Kuhn's 'exemplars' of scientific development (Kuhn, 1974 and 1977). The DC 3 airplane, the famous EDVAC electronic computer, the first microprocessor, the classic Mac and DOS-based personal computers are all examples of these basic designs.

If a particular field of technology is still characterised in terms of an 'immature' paradigm, as in the early days of personal computing, it can be expected that several versions of basic designs will be found. In case of growing technological maturity and increased economic competition or other social selection processes, variation decreases and it is to be expected that only one or a small number of basic designs will survive (Tushman and Anderson, 1986; Anderson and Tushman, 1990). In case of one basic design crowding out other designs (Tushman and Anderson, 1986) this leads to a so-called dominant design that serves as a guidepost for further development.

The emergence of one dominant design is understood by some (Abernathy and Utterback, 1978) to incorporate the best synthesis of several partial innovations, representing the technological frontier. If a particular basic design has become dominant, there will be technological improvements given the possibilities of that design and the technological 
trajectories associated with it are expected to follow a deterministic path. This deterministic interpretation of the emergence of dominant designs has, in our view, been correctly criticized in its neglect of the socioeconomic context of technological development. Anderson and Tushman (1990), Rosenkopf and Tushman (1994), but also Utterback in later work (Suarez and Utterback, 1995), stress the rivalry between designs where the selection by economic and social forces do not necessarily lead to dominant designs that embody the best technology. This implies that technological development is not of a deterministic nature as the improvements of a basic design take place in an environment in which complex interrelations between changes within a technological paradigm, market selection and choices made by individual companies set a broader context for understanding technological development.

The dynamic character of technological development is reflected in the cyclical movement of new and improved basic designs that emerge over time. As pointed out by Piore and Sabel (1984), Lee et al (1995) and Anderson and Tushman (1990), technological development is characterized by both diversification and patterns of branching or variation and longer periods of uniformity with mainly incremental change. A dominant design can be accepted for a period of time but it can be made redundant by new technological options and/or failing acceptance by changing demand. In the terminology of Rosenkopf and Tushman (1994) and van de Ven and Garud (1994), technology cycles lead not only to a selection of dominant designs but a new period of ferment can also create variation of a new generation of designs.

Within a technological paradigm, then, alternative designs are usually present during the initial development of that paradigm. The early PC industry, for example, provided the context for competition between two primary basic designs, the Apple Macintosh and the DOS configuration of the PC, with only a minor role to be played by other designs. ${ }^{3}$ The synthesis of the two most important basic designs emerged as the so-called 'Wintel' design, a label derived 
from the integration of the Microsoft Windows operating system on the Intel microprocessor. The Macintosh architecture was based on a very tight coupling of software and hardware, with the hardware fully integrated by a single assembler (Apple). In contrast, the Wintel design follows the architecture of the original IBM PC, with a much looser coupling of components and the notable use of an outside supplier (Microsoft) for the operating system software. Still, the two architectures were similar in other regards, notably in the use of a single microprocessor as the CPU and the ability to add peripheral equipment (modems, printers, and storage devices).

It is important to note that the innovator of a dominant design may not end up as the ultimate dominant firm in the market. While IBM was responsible for establishing the basic PC design and promoting its dominance in corporate computing, the rise of the PC 'clone' manufacturers in the mid-1980s, along with the increased marginalization of the Macintosh platform, provided an opportunity for the manufacturers of the basic PC components to assume ownership of the dominant design. Thus, by 1990, the technological trajectory of the IBM-compatible PC was controlled not by IBM, but by the developers of the two most critical components, the operating system (Microsoft) and the microprocessor (Intel). These new competitors eventually became the driving forces behind the dominant design in the PC industry. While there are multiple manufacturers of IBM-compatible PCs, they almost all share two key components; an Intel microprocessor and the Windows operating system.

Thus, the technological evolution of the PC industry can be portrayed as a series of major changes denoting the emergence of a mature technological paradigm and alternative basic designs, see table 1.

insert table 1 about here

\section{Some propositions on technology partnering between companies with competing basic}

\section{designs}


Upon initial observation, it would seem that technology alliances between firms with different basic designs would be very unlikely, as their strategic postures are based on different technical approaches or architectures. The technological overlap of these companies (Mowery, et al, 1998) can be expected to be so small that cooperation between them makes little or no sense. Indeed, when a new basic design first emerges, proponents of alternative designs will tend to discount the new design. Competition among basic designs is a sign of searches by different firms for architectures which leverage the greatest value. This value is assigned by users, and is therefore not only based on technical elegance or superiority. Instead, the value of a basic design is dependent upon many complex and interrelated factors, such as the availability of complementary technologies, skills, and capabilities which enable users to maximize their benefit from a particular design (Christensen and Rosenbloom, 1995). The degree of complementarity or overlap of technologies used in a new basic design, therefore, influences the likelihood of partnering (Hagedoorn, 1993; Mowery, et al, 1998).

The integration of certain elements of competing basic designs or the search for new designs through alliances can produce a range of strategic benefits:

- it can pool incremental innovations of basic designs to increase the overall improvement in key attributes of the integrated design,

- it enables the firms supporting different basic designs to combine their customer bases,

- it can pool new technologies which individually extend existing designs, but which in combination can constitute a new design.

However, partnering between companies that represent competing basic designs remains, almost by definition, a somewhat troublesome activity as long as these basic designs are excluding each other or as long as there is no clear understanding of which basic design will attract a larger user base. Once a particular basic design has become dominant, partnering is possible based on the acceptance of the dominance a particular basic design. We can expect 
that partnering will focus on new developments, combining some elements of competing basic designs in the light of expected future demand for new technological applications. In others words, the expected technological overlap for new applications increases the probability of future collaboration between companies. In that same context we expect companies to concentrate their partnerships on new developments through $R \& D$ that can be applied within their own product portfolio, ignoring joint production and joint marketing of existing products based on their competing designs (Carayannis et al, 1999; Hagedoorn, 1993). ${ }^{4}$

The above leads to the following propositions about technology partnering between proponents of competing basic designs, that will guide our exploratory study:

Proposition 1: Technology partnering between proponents of competing basic designs (rival companies) will only materialize after one basic design has become dominant.

Proposition 2: Technology partnering between proponents of competing basic designs (rival companies) will be mainly directed towards new technologies or complementary technologies that go beyond the core of the existing basic designs.

Proposition 3: Technology partnering between proponents of competing basic designs (rival companies) will mainly concentrate on $R \& D$ and ignore downstream elements of the value-chain such as manufacturing and marketing. 


\section{TECHNOLOGY ALLIANCES BETWEEN IBM AND APPLE}

\section{Data and methodology}

Our empirical analysis is based on two major sources of information: the MERIT-CATI database on technology alliances and two specific case studies built from a wide variety of public sources, newspapers, technical journals and interviews.

The MERIT-CATI data bank is a relational database which contains separate data files that can be linked to each other and provide (des)aggregate and combined information from several files. The CATI database contains information on more than 13,000 cooperative agreements involving some 6000 different parent companies during the period 1980-1996. It has information on each agreement and some information on companies participating in these agreements. Cooperative agreements are defined as common interests between independent (industrial) partners which are not connected through (majority) ownership. In the CATI database only those inter-firm agreements are being collected, that contain some arrangements for joint research or the transfer of technology. Joint research pacts, secondsourcing and licensing agreements are clear-cut examples. Information is also collected on joint ventures in which new technology is received from at least one of the partners, or joint ventures having some $R \& D$ program. The information is primarily related to those forms of cooperation and agreements for which a combined innovative activity or an exchange of technology is at least part of the agreement. However, many agreements also cover a wide range of other joint activities, such as production and marketing.

Relevant input of information for each alliance concerns: the number of companies involved, names of companies (or important subsidiaries), year of establishment, timehorizon, duration and year of dissolution, capital investments and involvement of banks and 
research institutes or universities, field(s) of technology, modes of cooperation, and some comment or available information about progress.

The most important fields in terms of frequency are information technology (computers, industrial automation, telecommunications, software, microelectronics), biotechnology (with fields such as pharmaceuticals and agro-biotechnology), new materials technology, chemicals, automotive, defense, consumer electronics, heavy electrical equipment, food $\&$ beverages, etc. All fields have major sub-fields.

Principal modes of cooperation are equity joint ventures, joint R\&D projects and technology exchange agreements. Each mode of cooperation has a number of particular categories. Depending on the very form of cooperation information is provided on the operational context, the name of the agreement or project, equity sharing, the direction of capital or technology flows, the degree of participation in case of minority holdings, some information about motives underlying the alliance (only for data up to 1989), the character of cooperation, such as basic research, applied research, or product development possibly associated with production and/or marketing arrangements.

In the context of the current study we used all information that we could find on the alliances in which both IBM and Apple are participating or have participated. Information was used on each entry described in the above.

The two case studies that we use to enter into a detailed analysis of the alliances between IBM and Apple are: Kaleida and Taligent. These two joint ventures, established in 1991, are the first major collaborative efforts between both companies that span a number of years of partnering and which are, therefore, good illustrations of the technology partnering between IBM and Apple. The case studies are based on literature search and interviews. For each case we first produced an extensive case report of approximately 10 pages and a set of separate 
notes. These reports were used as input for the shortened and focused versions that concentrate on the main topics of this paper and which are presented below.

Given the explorative and qualitative nature of our research this paper, we are not testing hypotheses in the usual way by means of statistical analysis of a large data set. Our current analysis focuses on a relatively small number of alliances between two companies, of which two cases are studied in some depth. Based on our understanding of the role of basic designs in the context of inter-firm technology partnering we formulated some propositions rather than hypotheses. In the following we will illustrate these propositions through a qualitative analysis of the technology alliances between IBM and Apple.

\section{Patterns in the alliances between IBM and Apple}

According to the information found in the MERIT-CATI database, IBM and Apple did not begin to form alliances with each other until the early nineties. Previous research (Hagedoorn and Schakenraad, 1992) indicates that both companies were active in forming alliances with others during the previous decade but they were found in different networks of partnering, having no direct and even no indirect ties with each other. For the period 1991- 1996 we found 19 technology alliances between IBM and Apple of which 12 are of a straightforward dyadic nature. Seven alliances between these companies include a number of other partners. Somewhat surprisingly this appears to be the largest number of technology alliances between two companies in information technology made during this period.

The first technology alliance between Apple and IBM that we found was established in 1991. By that time the DOS-based design for personal computing had become the dominant design. It is well known that in the earlier period when there were two fiercely competing designs the share of the Mac design in total personal computer sales was significant. By 1991 the share of Apple in personal computer sales had dropped to 11.2\%, while DOS-based 
systems had become the de-facto standard with a share of $85 \%$, as estimated by the market research firm Dataquest.

We found that about half of the total number of alliances in which both companies are involved is related to (tele-)communications and multimedia software, complementary technologies that are beyond the main activities of both companies. Most of these partnerships involve not only IBM and Apple but also companies such as AT\&T and Siemens. The other half of the IBM-Apple alliances deal with new data processing hardware and software, RISC (Reduced Instruction Set Computing) microprocessors, interfaces and local area networks.

This pattern is also reflected in the twelve 'exclusive' alliances between IBM and Apple, although there seems to be somewhat more emphasis on technologies directly relevant for data processing. Three of these Apple-IBM alliances concentrate on joint work on communication networks and multimedia, another three partnerships are related to RISC technology. Other alliances between these companies concentrate on the interface between IBM and Apple systems in terms of both hardware and software development. In recent years some joint work on new operating systems also started through a joint venture and a joint development agreement. We found four alliances in which Apple and IBM agreed to develop common standards, to develop connections between Apple and IBM computer systems or to design notebooks that can run both Mac and DOS-based software.

About two-third of these IBM-Apple alliances (12 partnerships) take the form of joint development or joint $R \& D$ agreements. Three alliances made in the early nineties can be characterized as joint ventures with a strong emphasis on $R \& D$. The strong $R \& D$ content of the IBM-Apple agreements becomes clear if we look at their third party agreements. In 1992 Apple, IBM and Toshiba formed a joint research pact to develop RISC microprocessors. In 1993 IBM and Apple entered into a joint development agreement with Novell to develop so- 
called object linking and embedding (OLE) software. In 1994 both companies and AT\&T and Siemens made a joint R\&D pact for the joint development of open, cross-platform specifications in computer-telephone-personal data interchange based on a standardization agreement that was made earlier that year. Also in 1994 Apple and IBM started to jointly develop on-line architecture for interactive multimedia with Scientific Atlanta. In 1995 Apple, IBM and Motorola made a joint development agreement for a common hardware reference platform specification. The same three companies together with Sun-Microsystems, Motorola, Netscape, BCE, Novell and Silicon Graphics entered into a joint development agreement in 1996 to develop a platform independent cryptography set of application programming interfaces (pica's).

The other alliances between Apple and IBM are mainly technology sharing agreements, referring to existing technologies or the transfer of IBM technology. Examples are found in the IBM licensing of RISC technology to Apple or the standardization agreement between Apple, IBM, Siemens and AT\&T on telecom protocols.

Given the particular emphasis on joint development, it will come as no surprise that with very few exceptions these alliances focus primarily on $R \& D$. There are some agreements that relate to technology sharing, but agreements where joint manufacturing or marketing are central to the agreement, with little attention for joint innovative activities, were not found.

\section{Two case studies: Kaleida and Taligent}

Early hints at a strategic relationship between Apple and IBM first emerged in 1985, when Apple Chairman Steve Jobs announced an offer of 'détente' with IBM at Apple's annual shareholder meeting. This amounted to an admission that the IBM PC had become the dominant design for business personal computers and that Apple would have to work with IBM to penetrate that market. On October 2, 1991, a number of alliance agreements between the two companies were signed, including: 
- a joint venture, called Taligent, to develop a next-generation operating system using the new 'object-oriented' approach to software engineering, and

- a second joint venture, called Kaleida, to create a standard for enabling PCs to process and display multimedia content.

These joint ventures were the most ambitious components of the alliances between these two companies. Each alliance represented an attempt in part to unseat Wintel as the dominant design for personal computers, using two different angles of attack. Kaleida would weaken the Wintel design by offering an alternative design based on the emerging capability of personal computers to process multimedia applications (programs incorporating text, sound, and full-motion video). More specifically, Kaleida proposed the development of a new 'authoring language', called ScriptX, which would allow software developers to manipulate and construct multimedia files and applications much more quickly than was possible with conventional programming techniques.

Taligent, at the same time, would completely supplant Microsoft Windows as the operating system component of the dominant PC design. By using object-oriented programming, an experimental software development technique believed to be much more efficient than traditional programming, Taligent hoped to convince large numbers of independent software vendors to abandon the Windows platform and instead develop their applications specifically for the new Taligent system.

Soon after Kaleida and Taligent began operation in 1992, both ventures suffered from conflicts between the corporate cultures and technical strategies of the two parent companies. Kaleida was torn by a fundamental conflict in the approaches of IBM and Apple to the multimedia market (Freedman, 1992). While IBM preferred a measured approach, based on a range of technologies, Apple viewed Kaleida as a vehicle for extending the reach of its existing multimedia technology, called QuickTime. Eventually, IBM's approach won, as 
ScriptX was developed with little reliance on QuickTime. IBM succeeded in forcing this approach onto Kaleida by engineering the replacement of Kaleida's original CEO, Mr. Nathan Goldhaber, with a long-time IBM executive, Mr. Michael Braun, in July of 1993 (Weber, 1993). Several former Apple executives left the top management team of Kaleida at the same time.

By late 1993, Kaleida began to show the stress from pursuing its ambitious agenda. The company attempted to combine its strategy of developing ScriptX for multimedia PCs with a parallel effort to create a version of ScriptX to run on interactive multimedia television systems (which would be operated by cable and telephone companies, according to the dominant vision of the telecommunications industry at that time), as well as one for portable handheld computers or 'Personal Digital Assistants'. In May 1994, the IBM and Apple representatives on the board of directors of Kaleida order the venture to scale back its development efforts, dropping its program to create a multimedia operating system for interactive television systems. Kaleida did not ship its first full version of ScriptX until December 1994, more than three years after the inception of the venture. By the time ScriptX reached software developers, it had been surpassed by other multimedia authoring systems, including Apple's own QuickTime system. Kaleida was finally dissolved on November 17, 1995, with most of its personnel and technology absorbed by Apple.

Taligent was also forced to change its direction several times during its existence. As with Kaleida, Taligent's top management team was not selected until mid-1992, several months after the joint venture agreement was signed. By December 1992, Taligent began changing its strategy, positioning the Taligent system as an add-on to the existing Apple and IBM operating systems (Macintosh, OS/2 and AIX) rather than a completely new system. This shift was caused by two competing pressures: first, the difficulty and resources involved in developing a completely new operating system, and second, the reluctance of computer users 
(particularly in large corporations) to discard their sunk investments in Wintel hardware and software in favor of the new Taligent system. Thus, the 'network effects' of the dominance of the Wintel standard worked to maintain the dominance of that design in the face of the challenge from Taligent (Arthur, 1996). By late 1993, this approach had been modified to develop Taligent as a set of frameworks for object-oriented software development, which would be adapted to existing operating systems (Cortese and Foley, 1993).

Taligent received a boost in January 1994, when Hewlett-Packard joined as the third equity partner in the venture. The new set of frameworks promised by Taligent is labeled the 'CommonPoint' architecture for object-oriented programming, running on operating systems from IBM, Apple, and HP, as well as Windows 95. However, before the architecture was fully developed, IBM and Apple terminated Taligent in December 1995.

An analysis of each case shows that they shared similar goals in four respects: extending the capabilities of PCs, leveraging parallel R\&D efforts, unifying the basic PC designs at Apple and IBM, and attempting to undermine the dominance of the Wintel design.

\section{Extending the capabilities of PCs}

As mentioned above Kaleida was intended to develop ScriptX, which would facilitate the development of multimedia PC programs by simplifying the integration of multimedia content (audio, video, and animation) into applications. The introduction of the CD-ROM drive for the personal computer in 1991 created the possibility that personal computers could store and display full-motion video and complex animation sequences, a capability previously limited to high-end workstations or even more powerful machines. The major barrier to creating multimedia programs was that it was very difficult to write applications integrating extensive video, sound and graphics files. A few companies had produced 'authoring systems' which could manipulate such files in pre-determined structures. Kaleida promised to create a form of authoring system which was more flexible and more simple than existing 
products. This would spur the development of multimedia software products, which would in turn prompt more users to purchase multimedia-capable machines, making multimedia part of the de facto standard for PC designs.

Taligent promised to extend the basic design of the PC by integrating a new technology, object-oriented software engineering, into a critical component of the design, the operating system software. Object-oriented programming does not focus on writing software line by line, as in traditional programming, but instead links together simple pre-programmed 'software objects' into more sophisticated routines. This enables these programs to reuse software components, speeding the process of software development. Object software also opened the possibility of creating applications which could run on different operating systems, by writing the programs to use the existing software objects for each system. Thus, the same application could be run on both the Windows and Macintosh system without modification, whereas traditional programming required software developers to create separate versions of each application for each operating system.

\section{Leveraging parallel $R \& D$ efforts}

Both Kaleida and Taligent built on existing R\&D efforts by Apple and IBM in multimedia and object-oriented software, respectively. They were designed to eliminate some of the redundancies in the parallel development projects, saving the resources of the alliance partners.

Previous to the alliance, IBM had launched a new development program called Fireworks Partners. This initiative, headed by Mr. Michael Braun (who later became CEO of Kaleida), made strategic investments in multimedia software companies, so that the technology from those companies could be integrated into IBM's own multimedia software. Apple had recently released its own multimedia authoring system, called Quicktime, which the company licensed to Kaleida for inclusion in ScriptX. 
The Taligent software, on the other hand, was built primarily on an object-oriented operating system called Pink, which Apple had been developing for some time. While IBM was relatively weaker in object-oriented technology, it had formed a joint venture with a startup firm, Metaphor Computer Systems, to create a similar operating system. This joint venture, called Patriot Partners, was dissolved so that its technologies could be used by Taligent.

\section{Unifying basic PC designs}

A key goal of both Kaleida and Taligent was not simply to share technologies, but to enable the creation of new software which would run on both the Apple Macintosh operating system and on IBM's OS/2 operating system. By 1991, both of those systems were rapidly losing market share to Microsoft Windows. Extant trends almost assured that the decline would continue without some major strategic change. As Windows grew to become the dominant operating system, Macintosh and OS/2 were dividing a smaller share of the market among themselves. It was clear that software developers would begin to abandon these two systems, because neither would have a sufficient user base to recoup the costs of developing applications for those systems. Integrating the Macintosh and IBM basic designs for the PC would possibly stave off that decline long enough for Apple and IBM to find a way to break the dominance of the Wintel design.

Kaleida proposed to unify the two basic designs by making multimedia programs completely interoperable with both the Macintosh and OS/2 operating systems. Software developers would be able to create a single version of each application to serve the Macintosh and OS/2 software markets simultaneously, leading more developers to write for this combined market. Also, users of these two operating systems would benefit, as they could run programs written for either system, thus expanding the range of available software. To promote the adoption of ScriptX, Kaleida solicited members for its Worldwide Developers 
Program. Software firms which joined the program would receive application development tools, training, technical information, and marketing support for ScriptX products.

Taligent would further unify the IBM PC and Macintosh designs by moving both companies to support a single operating system. In consideration of existing IBM and Apple customers, Taligent would also include software adapters, so that programs written for the Taligent system would still work on either the OS/2 or Macintosh platforms. Therefore, the introduction of Taligent would not force users to abandon their sunk investment in these two previous systems. By gradually migrating both software developers and PC users to Taligent, Apple and IBM would be able to combine their customer bases and better compete with the growing world of Wintel supporters. Taligent also engaged in a marketing campaign to garner support for the Taligent 'application framework' (the precursor to the Taligent operating system) among independent software vendors, and began soliciting new equity partners for the venture starting in early 1992, just months after the venture started operations.

\section{Undermining the dominance of Wintel}

As a final goal, both Kaleida and Taligent were expected to help counter the growing popularity of Wintel. In multimedia, Wintel machines had a distinct disadvantage in that incompatibilities existed between the multimedia peripherals used with Wintel machines (sound cards, video accelerators, CD-ROM drives, and others). Therefore, multimedia programs written for the Wintel platform did not always work on every multimedia-capable Wintel machine, because of the lack of standards among peripherals. To avoid a similar fate, Kaleida formed the Manufacturers Alliance for (primarily Asian) companies who would design peripherals and other computing hardware for compatibility with the ScriptX system. This would give PCs which met the standards set by Kaleida an advantage in the marketplace over Wintel PCs. 
Kaleida also attempted to undermine Wintel by extending its reach to platforms other than the PC. Toshiba agreed to make a handheld computer which would run ScriptX applications. In June 1993, Kaleida formed joint venture with Motorola and Scientific-Atlanta to create hardware for interactive cable television systems which would run ScriptX programs. Therefore, Kaleida tried to extend its potential customer base even further by addressing nonPC markets.

Taligent represented a more direct attack on the Windows component of the Wintel dominant design. In January 1994, Hewlett-Packard became the third equity partner in Taligent, and pledged to make its future workstations and personal computers compatible with the Taligent system. In June 1994, Taligent revealed a system for running Taligent programs on top of Windows NT, the next generation of the Windows OS (NT stands for 'new technology') aimed at corporate computer users. Therefore, Taligent software developers would be able to sell their programs to users of personal computers from Apple, IBM, Hewlett-Packard, plus the many units running the Windows NT operating system. This would erode the base of developers writing exclusively for the NT platform, thus undermining Microsoft's dominant position in the software industry.

\section{Epilogue}

Neither venture ended up having a lasting impact on the dominant design of the personal computer, but their legacies did form part of later efforts to undermine the Wintel design. Kaleida's ScriptX was adopted by Apple into later versions of its QuickTime multimedia system, which has become one of the two dominant formats for multimedia files available over the World Wide Web. Taligent's development efforts became part of a program at IBM called the San Francisco Project, which helped to spur adoption of object-oriented programming among corporate computer users. At the same time, parts of the Taligent technology were folded into a new software development format at Sun Microsystems, which 
became known as Java. Java was then used as the basis for a new design of personal computing systems, called 'network computers', which may become the dominant design if the Wintel platform would begin to weaken.

In contrast to these efforts, other components of the 1991 accord between Apple and IBM did have some lasting effect on dominant designs in the computer industry, although not the intended effects. One major venture, which developed a new architecture for microprocessors based on the RISC design (Reduced Instruction Set Computing), eventually included Motorola (Apple's primary supplier of microprocessors) and became known as the PowerPC consortium. The RISC-based PowerPC chip did not achieve widespread usage, as it was adopted only by Apple in its new lines of Macintosh computers after 1995. However, IBM leveraged the development of the PowerPC into its own line of RISC-based computers, the RS/6000, which has been widely adopted as a powerful 'midrange' computer system for corporations. While the PowerPC venture had minimal impact on consumer or personal computers, it helped IBM to regain control of the more profitable corporate computing market.

A final important consideration is the extent to which these collaborations were affected by the fates of their primary parents, Apple and IBM. Both companies began experiencing severe financial difficulties starting in 1993, shortly after Kaleida and Taligent were formed. In fact, it is likely that the top management of both firms knew of their companies' impending problems in 1991, raising the possibility that these joint ventures were simply a desperate attempt to forestall financial collapses brought on by the continued success of the Wintel alliance. This would explain to some extent the inability of each venture to set a coherent strategic direction, as they operated during a period when their parents were in 'crisis mode' (Slater, 1991). 


\section{DISCUSSION AND CONCLUSIONS}

Our analysis of the technology alliances between IBM and Apple largely supports the propositions introduced in the above. The history of the collaboration between these companies shows that their alliances did not materialize until the early nineties when the DOS-based paradigm had become the dominant and the Wintel basic design was clearly on its way to becoming the new dominant design. The 'détente' that was offered by Apple and which gradually improved the relationship between both companies was merely a sign of the acceptance by Apple that IBM had established a de facto standard in the area of business computing. Once Apple and IBM started to cooperate through technology alliances they became, much to our surprise, main collaborators in the information technology industry. According to our data these companies have the largest number of technology alliances made between two companies in the information technology industry. Most of these alliances are bilateral but in some agreements we find third parties. The nature of these IBM-Apple partnerships and the growth in the number of formal agreements between both companies, be it of a dyadic or of an multilateral nature, supports our first proposition. Technology partnering between these proponents of competing basic designs only materialized several years after the DOS-based paradigm was becoming dominant.

The emphasis in a number of the 'exclusive' technology alliances between these two companies made during the early nineties was on the interface between existing IBM and Apple systems, although new operating systems were expected to provide more opportunity for future interfaces. However, the majority of the alliances between these companies, whether they include others or only IBM and Apple, focus on telecom applications, the integration of multimedia capabilities, and the development of object-oriented software and RISC processing technologies. The part of our analysis that looked at the technological direction and content of these agreements appears to support our second proposition. 
Technology partnering between IBM and Apple was largely directed towards new technological developments and technologies that went beyond the core of the Wintel PC design of the time.

Given this emphasis on new technologies as the major topic for joint work through these IBM-Apple alliances, it is not surprising that the focus in most of these partnerships is on joint R\&D. Both in the multilateral and the bilateral alliances joint marketing and manufacturing plays only a limited role. This finding supports our third proposition, which suggests that technology partnering between companies with competing basic designs will mainly concentrate on R\&D with little or no attention for manufacturing and marketing.

However, the analysis by means of the two case studies also qualifies some of the assumptions behind the propositions introduced in this paper and some of the general findings. For instance, both Kaleida and Taligent were engaged in marketing their technologies to software and hardware companies, and eventually involved the production and distribution of their products. Still, the focus of investment for these ventures was the development of new technologies, which would then be integrated back into new products from the two parent firms. ${ }^{5}$ Our findings based on the case studies also demonstrate that partnerships between companies with competing basic designs that focus mainly on the current dominant design to the detriment of the other design run the risk of becoming obsolete or being integrated by the company that is closest to the dominant design. ${ }^{6}$ If the emphasis in the partnership changes from the search for new technologies to incremental innovation based on existing technologies related to the dominant design, the result in terms of termination of the alliance seems to be identical. Therefore, we can expect that technology alliances between proponents of competing basic designs will break down as the cooperation begins to focus on the design of one company to the detriment of the other. Viability of alliances between companies that have competing basic designs seem to depend on the 
delicate acceptance of the dominant design of others and the technological scope of the alliance aimed at new designs and other technological developments that might eventually lead to a new technological paradigm. 


\section{References}

Abernathy W.J. and J.H. Utterback, 1978, Patterns of innovation in technology, in Technology Review, 80, pp. 40-47.

Anderson, P. and M.L. Tushman, 1990, Technological discontinuities and dominant designs: a cyclical model of technological change, in Administrative Science Quarterly, 35, pp. 604633.

Arthur, W. B., 1996, Increasing returns and the new world of business, in Harvard Business Review, July-August ,pp. 100-109.

Carayannis, E. G., R. L. Samanta Roy and J. Alexander, 1999, The speed and acceleration of technological innovation: a co-opetitive dynamics perspective of the small satellite industry, in Proceedings of the July, 1999 Portland International Conference on the Management of Engineering and Technology (PICMET).

Christensen, C.M. and R.S. Rosenbloom. 1995, Explaining the attacker's advantage: technological paradigms, organizational dynamics and the value network, in Research Policy, 24, pp. 233-257.

Clark, N. and C. Juma, 1987, Long-run economics - an evolutionary approach to economic growth, London, Francis Pinter.

Cortese, A. and Foley, M., 1993, Taligent shifts OS gears to system add-on focus, in PC Week, 25 October.

Dosi, G., 1982, Technological paradigms and technological trajectories, in Research Policy, 11, pp. 147-162.

Ferguson, C.H. and C.R. Morris, 1994, Computer wars: The fall of IBM and the future of global technology, New York, Times Books

Flamm, K., 1988, Creating the computer: Government, industry and high technology, Washington, The Brookings Institution. 
Freedman, B., 1992, IBM, Apple discord could KO Kaleida, in PC Week, 16 March.

Freeman, C. and L. Soete, 1987, Technical change and employment, Oxford, Blackwell. Hagedoorn, J., 1989, The dynamic analysis of innovation and diffusion - A study in process control, London, Pinter Publishers.

Hagedoorn, J., 1993, Understanding the rationale of strategic technology partnering: interorganizational modes of cooperation and sectoral differences, in Strategic Management Journal, 14, pp. 371-385.

Hagedoorn, J. and J.S. Schakenraad, 1992, Leading companies and networks of strategic alliances in information technologies, in Research Policy, 1992, 21, pp. 163-190.

Jorde, T. M. and D. J. Teece, 1990, Innovation and cooperation: implications for competition and antitrust, in Journal of Economic Perspectives, 4, (3), pp. 75-96.

Kuhn, T.S., 1974 (1962), The structure of scientific revolutions, Chicago, Chicago University Press.

Kuhn, T.S., 1977, The essential tension, Chicago, Chicago University Press.

Lee, J-R, D.E. Neal, M.W. Pruett, H. Thomas, 1995, Planning for dominance: a strategic perspective on the emergence of a dominant design, R\&D Management, 25, pp.3-15. Malerba, F., Torrisi, S., and Tunzelmann, N. von, 1991, Electronic computers, in C. Freeman, M. Sharp and W. Walker (eds.), Technology and the future of Europe: Global competition and the environment in the 1990s, London, Pinter.

Mowery, D.C., J.E. Oxley, B.S. Silverman, 1998, Technological overlap and interfirm cooperation: implications for the resource-based theory of the firm, Research Policy, 27, pp. 507-523.

Nelson, R.R. and S.G. Winter, 1977, In search of useful theory of innovation, in Research Policy, 6, pp. 36-75. 
Piore, M.J. and C.F. Sabel, 1984, The second industrial divide - possibilities for prosperities, New York, Basic Books.

Rosenkopf, L. and M.L. Tushman, 1994, The coevolution of technology and organization, in J.A.C. Baum and J.V. Singh (eds.), Evolutionary dynamics of organizations, New York, Oxford University Press, pp. 403-424.

Sahal, D., 1981, Patterns of technological innovation, Reading (Ma), Addison-Wesley. Slater, M., 1991, Apple, IBM, and Motorola sign contracts for far-reaching collaboration, in The Microprocessor Report, 16 October.

Suarez, F.S. and J.M. Utterback, 1995, Dominant designs and the survival of firms, in Strategic Management Journal, 16, pp. 415-430.

Tushman, M.L. and P. Anderson, 1986, Technological discontinuities and organizational environments, in Administrative Science Quarterly, 31, pp. 439-465.

Van de Ven, A.H. and R. Garud, 1994, The coevolution of technical and institutional events in the development of innovation, in J.A.C. Baum and J.V. Singh (eds.), Evolutionary dynamics of organizations, New York, Oxford University Press, pp. 425-443.

Weber, J., 1993, New top exec named at Apple-IBM venture, in The Los Angeles Times, 16 July. 
Table 1 Development of the current technological paradigm in the PC industry (19841996) and its basic designs

\section{$\underline{\text { Technological paradigm }}$}

Competing approaches

Macintosh (Apple)

DOS-based (IBM-Microsoft-Intel)

Dominant approach

DOS-Windows

$\underline{\text { Basic designs }}$

Competing basic designs

Apple I and II

DOS PC

Dominant design

Wintel PC
Key features

User-friendly, graphical, elegant design

Technically-complex, text-based, cost-effective

$\underline{\text { Key features }}$

User-friendly, but with underlying complexity

\section{$\underline{\text { Key features }}$}

Integrated hardware and software, tightlycontrolled proprietary standards

Separate hardware and software, open standards

$\underline{\text { Key features }}$

Separate hardware and software, more proprietary standards, DOS platform 
1. The following information on technological development can be found in many sources, see e.g. Ferguson and Morris (1994), Flamm (1988), Malerba et al (1991).

2. This concept is also comparable to the notion of a technological regime (Nelson and Winter, 1977) or that of a technological guidepost introduced by Sahal (1981). The notion of a meta-production function refers to "... a frontier of achievable capabilities, defined in the relevant economic dimensions, limited by physical, biological and other constraints, given a broadly defined way of doing things ..." (Nelson and Winter, 1977, p. 57).

3. Some examples of other, failed and by now largely forgotten, designs are the Osborne computer, the first attempt to create a portable PC, the TRS-80 from Tandy/Radio Shack, the PET by Commodore Computers, the Franklin Ace (a clone of the Apple II), ATARI's Applelike 'clone' and many $75 \%$ - 95\% IBM compatible machines that were found during the 1970 's and 1980's.

4. It has to be stressed that we only refer to technology partnerships and that our current analysis does not include collusive agreements that focus on production restriction, price setting, limited introduction of new products, etc. Also the effect of government anti-trust policy, which played no role in this particular context, is not included in our analysis (see Jorde and Teece, 1990).

5.It is interesting to note that neither partner succeeded in leveraging the technologies developed by Kaleida and Taligent to any great degree. Apple integrated some aspects of ScriptX into later versions of its QuickTime multimedia system, and IBM used elements of Taligent in a later project in object-oriented software.

6. For instance, in the months leading up to the termination of the two ventures, the top management and strategic direction of both became dominated by IBM rather than Apple. This contributed to dissatisfaction among the Apple employees in both ventures, which in turn accelerated the demise of the two collaborations. 